\title{
Patients' Experience of Using Eye Drop Guide Device to Aid Self-Administration of Glaucoma Medications
}

This article was published in the following Dove Press journal: Clinical Ophthalmology

\author{
Darin Sakiyalak (iD) \\ Sirinya Kobwanthanakun (D) \\ Department of Ophthalmology, Faculty of \\ Medicine, Siriraj Hospital, Mahidol \\ University, Bangkok, Thailand
}

Purpose: To determine the characteristics of the patients who preferred using the eye drop guide (EDG) regularly and their opinions toward the guide in order to select the patients for prescribing the EDG appropriately.

Patients and Methods: Fifty-seven glaucoma patients who completed the primary study, "The effect of 'eye drop guide' on the success rate of eye drop self-instillation in glaucoma patients", were included. Patients' instillation techniques, routine instillation or using the EDG, were chosen independently. After 4-6 months, they were interviewed about the frequency of EDG use and their rating scores toward the guide in 4 aspects including aiming aids, contamination prevention, reduction of drop waste, and ease of use. The differences in opinion scores between each frequency group and the factors associated with the regularity of EDG use were statistically analyzed.

Results: Of fifty-seven patients completing the interview, $19.3 \%$ used the EDG everyday, while $45.6 \%$ had never used the EDG. The nonusers rated significantly lower scores in all aspects ( $\mathrm{p}$-value $<0.005)$. From multivariate analysis, the factors associated with the preference not to use the EDG were administering in supine position (p-value $<0.001$, adjusted OR 34.866, 95\% CI 4.974-244.412) and more than one eye drop use (p-value = 0.048, adjusted OR 5.280, 95\% CI 1.018-27.396).

Conclusion: The EDG should be selectively prescribed for the particular patients who had one medication and performed instillation in sitting or standing position. Although the regular EDG users tended to have positive opinions on the EDG, their long-term compliance with the guide was underinvestigated.

Keywords: eye drop administration, eye drop guide, self-instillation, glaucoma

\section{Introduction}

Glaucoma is a group of diseases characterized by a specific pattern of progressive damage to the optic nerve, resulting in optic atrophy and blindness. Lowering intraocular pressure (IOP) is the only proven treatment to help prevent or delay visual functional impairment from glaucomatous damage. ${ }^{1-5}$ Ocular hypotensive drugs are the most common treatment initiated for IOP reduction. Although many approaches for sustained drug delivery to the eye have been developed, topical administration remains the first-line as well as the mainstay of treatment. Topical eye drops are mostly accepted due to their simplicity, relatively safety, and noninvasive route of administration. However, the patient's adherence to prescribed medications is essential for the success of glaucoma treatment. Similar to other
Correspondence: Darin Sakiyalak Medicine, Siriraj Hospital, Mahidol University, I4th Floor, Syamindra Building, 2 Wanglang Road, Bangkoknoi, Bangkok 10700, Thailand

Tel +6624198037

Fax +6624111906

Email dsakiyalak@gmail.com 
chronic progressive diseases, high non-adherence rates of at least $25 \%$ among glaucoma patients have been reported in various studies. ${ }^{6-8}$ Furthermore, compliance with the topical eye drops has unique challenges compared to oral medications, especially in the patients who self-administer their eye drops. The ability to properly administer a medication into the eye, along with using the correct number of prescribed eye drops at the right time, are necessary for treatment success. Failure to instill eye drops correctly is associated with treatment failure, excessive dose of medication, bottle contamination, and corneal abrasion that can possibly lead to a corneal ulcer. ${ }^{9,10}$

Techniques for eye drop self-administration include aiming the drops, tilting the head back, avoiding the bottle tip contamination, and gently squeezing to expel a drop from the bottle. The instillation aids have been developed to improve one or more of these difficulties. ${ }^{11}$ In Thailand, the "Thai Eye Drop Guide (EDG)" has been developed to aid eye drop self-administration by improving eye drop aiming and preventing bottle tips from contaminating the periocular tissue. In our previous study, we demonstrated that the success rates of eye drop self-instillation were not statistically significant between EDG device and the traditional technique when the patients were properly trained with each technique. ${ }^{12}$ After the study, the devices were given to all participants. The decision to continue using the device were as per their preference. From observation, there were varieties of opinions toward the device. Some patients who did not succeed in self-instillation using the EDG device in the study preferred to continue using the device after the study while some patients who succeeded with the device in the study refused to use it afterward. Their reasons, for example, they felt more confident that the tip of the eye drop bottle would not touch their eyes.

In this study, we investigated which patients continued using the EDG regularly and patients' opinions toward the device. We also surveyed the patients' experiences and their priorities in selecting drug-delivery devices. The results of this study will help to select the patients for EDG prescription in order to achieve the goal of glaucoma treatment.

\section{Materials and Methods Thai Eye Drop Guide (EDG)}

Thai EDG (patent number 6555) was made of lightweight, chemically inert, thermoplastic polystyrene (PS) (Figure 1). It has the shape and size of a regular eye wash cup,

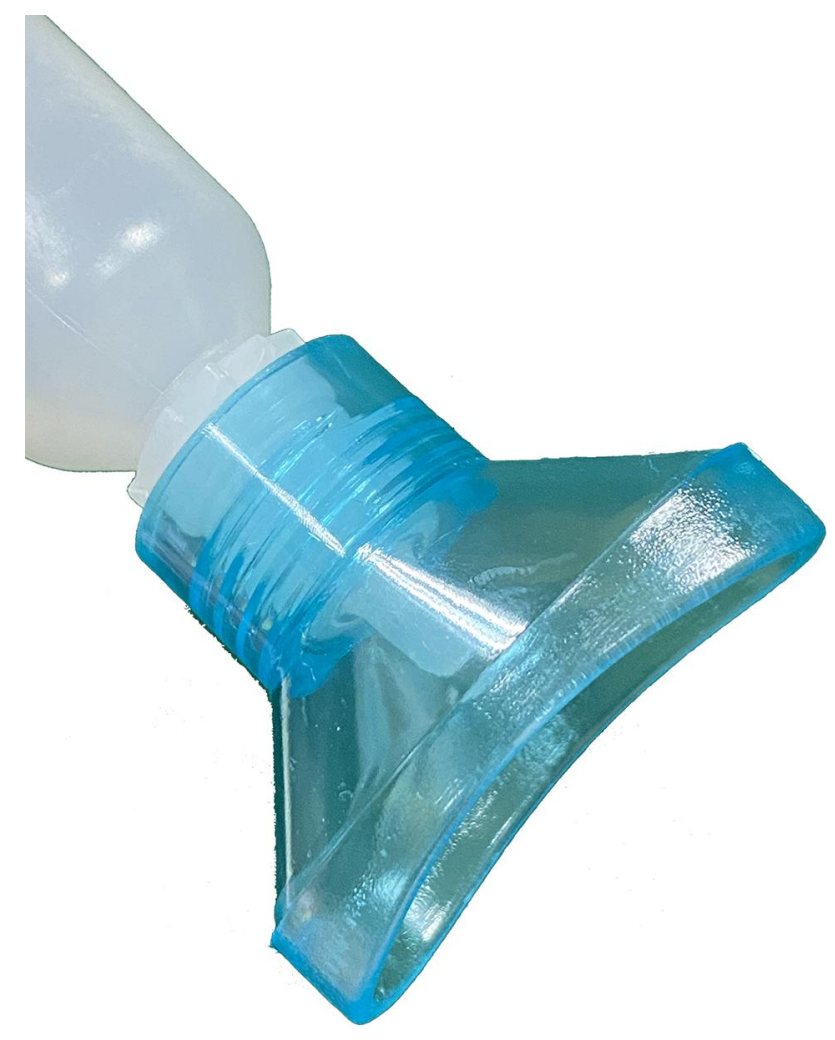

Figure I Eye Drop Guide.

with a curved rim to fit the orbit of the eye. It's not expensive and washable.

\section{Subjects Selection}

The study subjects were all of the participants who had completed the primary study "The eye effect of the Thai "Eye Drop Guide" device on the success rate of eye drop self-instillation by glaucoma patients" conducted in the Ophthalmology Department of Siriraj Hospital.

Subjects included were patients above 18 years old, diagnosed with glaucoma for more than 3 months, and who regularly self-instilled the eye drops in their eyes. Participants were excluded if they refused to participate in this study or could not be contacted by telephone.

Demographic and personal data collected for each participant included age, sex, educational status, duration of glaucoma, eye(s) in which eye drops were used, number and types of topical anti-glaucoma medications, number of medication bottles that fitted with the EDG device, bestcorrected visual acuity (BCVA), visual field status; mean deviation score (MD). Data collected from the previous study included success in eye drop self-instillation by both "Traditional" and "EDG" technique. 
After the end of the primary study, the devices were given to all patients. Self-instillation by Traditional technique or EDG use were to be chosen, to the patients' preference. After 4 to 6 months, the telephone interviews were performed.

\section{Telephone Interview}

We collected the data by using telephone interviews due to the variation in subjects' educational status and illiteracy. Two interviewers were used in this study. They were prepared and practiced before performing the interview. A telephone script was divided into 3 parts. The first part was the telephone consent. The second part was the detail about self-instillation, frequency and preferred position. Subjects were classified into 3 groups depending on the frequency of EDG use when they performed selfinstillation; group I (Always) for the patients using the guide every day, group II (Sometimes) for the patients using the guide 1 to 6 days per week, and group III (Never) for the patients who had never used the guide. The third part was about the patients' opinions toward the guide, in the aspects of aiming aids, contamination prevention, reduction of drop waste, and ease of use. Rating scales were used to assess the subjects' opinions. A score of 1 to 5 was used for positive opinion about the EDG, while a score of -1 to -5 was used for negative opinions. For example, in the aspect of ease of use, if the patients feel easier to instill with the device, the score of 1-5 will be offered to the subjects. The score of 1 represented the minimal ease they gained, while 5 represented the maximal ease. Conversely, if they feel more difficulty in using the device, the score of -1 to -5 will be offered. The score of -1 indicated the minimal difficulty, whereas -5 indicated the maximal difficulty. A score of 0 represented no advantages nor disadvantages of the device over Traditional technique. Details of the rating scales were instructed to all participants before asking each question. At the end of the interview, we used the open-ended questions to identify limitations of the device in the participants' opinions.

\section{Statistical Analysis}

The associations between two categorical variables were determined using Fisher's exact test. (baseline characteristics and frequency of EDG use) The differences between two independent groups were compared using the MannWhitney $U$-test. (group I vs II, group II vs III and group I vs III). Factors found to have statistical significance in univariate analysis with $\mathrm{p}$-value $\leq 0.1$ were further analyzed using multivariate logistic regression. P-value less than 0.05 was considered statistically significant.

\section{Results}

We enrolled the participants 4-6 months after the primary study. Of all initial 59 patients, telephone interviews were completed for 57 patients. We could not contact one patient in a time limit and one patient refused to participate in the study. Demographic characteristic of study participants is presented in Table 1. After interviewing, the patients then were classified into 3 groups according to the regularity of EDG use. Group I, eleven participants (19.3\%) always used the EDG device when administering eye drops at home. Group II, 20 participants (35.1\%) used the EDG device regularly, at least 1 time a week, but not every day. Finally, Group III, 26 participants (45.6\%) had never used it after completing the primary research. The characteristics of each group are shown in Table 2.

Baseline and clinical characteristics, such as position when routinely administering eye drops, number of eye drops used, and visual field MD scores, tended to be different among the groups, with a $\mathrm{p}$ value $\leq 0.1$ in univariate analysis (Table 2).

Table I Demographic Characteristic of Participants

\begin{tabular}{|c|c|}
\hline Characteristics & \\
\hline Mean age, years (SD) & $69.35(12.35)$ \\
\hline Gender, male: female & $27: 30$ \\
\hline BCVA, median (range) ${ }^{a}$ & $\log M A R \quad 0.3(\log M A R 3-0)$ \\
\hline MD score, median (range) ${ }^{\mathrm{b}}$ & $-5.13(-30.79$ to 0.66$)$ \\
\hline Mean duration of glaucoma, years (SD) & $6.30(5.23)$ \\
\hline Number of glaucoma eye drops, mean (SD) & I.75 (0.78) \\
\hline EDG fitted with all eye drop bottles, n (\%) & $8(14.04)$ \\
\hline \multicolumn{2}{|l|}{$\begin{array}{l}\text { Preferred position when administration eye } \\
\text { drop, } \mathrm{n}(\%)\end{array}$} \\
\hline - Supine & $17(29.8)$ \\
\hline - Sitting & $31(54.4)$ \\
\hline - Standing & $9(15.8)$ \\
\hline \multicolumn{2}{|l|}{ Educational level, n (\%) } \\
\hline - Elementary school & $3(5.26)$ \\
\hline - Junior high school & $23(40.35)$ \\
\hline - High school & $10(17.54)$ \\
\hline - College and higher & $21(36.84)$ \\
\hline Success rate with $\mathrm{EDG}^{\mathrm{c}}$ & $63.2 \%$ \\
\hline Success rate with Traditional technique ${ }^{c}$ & $68.4 \%$ \\
\hline
\end{tabular}

Notes: ${ }^{a}$ Best corrected visual acuity in the worse eye of the participant. ${ }^{b}$ Humphrey visual field mean deviation score. 'Success rates of eye drops selfadministration from the previous study. ${ }^{10}$ 
Table 2 Characteristic of Participants in Each Group

\begin{tabular}{|c|c|c|c|c|}
\hline Characteristics & Group I: Always ${ }^{\mathbf{a}}$ & Group II: Sometimes ${ }^{b}$ & Group III: Never ${ }^{c}$ & P value ${ }^{d}$ \\
\hline Age & & & & 0.395 \\
\hline - $\geq 70$ years & 4 & 11 & 16 & \\
\hline$\bullet<70$ years & 7 & 9 & 10 & \\
\hline Gender & & & & 0.026 \\
\hline - Male & 8 & 5 & 14 & \\
\hline - Female & 3 & 15 & 12 & \\
\hline BCVA in the worse eye & & & & 0.850 \\
\hline - Better than $3 / 60$ & 10 & 17 & 24 & \\
\hline - $3 / 60$ or worse & I & 3 & 2 & \\
\hline MD score & & & & 0.107 \\
\hline - Better than -15 & 11 & 15 & 18 & \\
\hline - -15 or worse & 0 & 5 & 8 & \\
\hline No. of glaucoma medications & & & & 0.121 \\
\hline - I eye drop & 3 & 3 & 1 & \\
\hline - More than I eye drops & 8 & 17 & 25 & \\
\hline Medication bottles fitted with EDG & & & & 0.156 \\
\hline - All medications & 3 & 3 & 2 & \\
\hline - Some medications & 1 & 5 & 12 & \\
\hline - None of medications & 7 & 12 & 12 & \\
\hline Position when instillation & & & & $<0.001$ \\
\hline - Standing & 4 & 5 & 0 & \\
\hline - Sitting & 7 & 13 & II & \\
\hline - Supine & 0 & 2 & 15 & \\
\hline Educational level & & & & 0.939 \\
\hline - Lower than high school & 5 & 10 & II & \\
\hline - High school or higher & 6 & 10 & 15 & \\
\hline Administration success with $\mathrm{EDG}^{\mathrm{e}}$ & & & & 0.591 \\
\hline - Success & 7 & 11 & 18 & \\
\hline - Not success & 4 & 9 & 8 & \\
\hline Traditional administration success ${ }^{e}$ & & & & 0.701 \\
\hline - Success & 8 & 12 & 19 & \\
\hline - Not success & 3 & 8 & 7 & \\
\hline
\end{tabular}

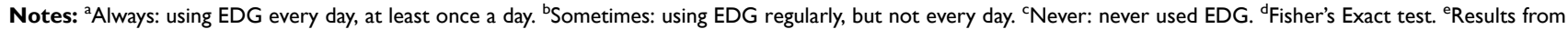
primary study.

Abbreviations: BCVA, best corrected visual acuity; EDG, eye drop guide; LogMAR, logarithm of the minimum angle of resolution; MD, visual field mean deviation score.

In multiple logistic regression analysis, we assess the association between these characteristics and the frequency of the EDG use (Table 3). The position when administering eye drops and the number of antiglaucoma eye drops were found to be independently associated with the preferred technique for eye drop selfadministration. Participants who used more than 1 eye drop were more likely to prefer only the Traditional technique ( $\mathrm{p}=0.048$, adjusted OR 5.3, 95\% CI 1.0-27.4). Also, the participants who instilled eye drops in a supine position were more likely to abandon the device ( $\mathrm{p}<0.001$, adjusted OR 34.9, 95\% CI 4.9-244.4).

We explored the patient's opinions toward the EDG in 4 aspects; aiming aids, contamination prevention, reduction of drop waste, and ease of use. The distribution of patients' rating scores from each group are shown in Figure 2A-D.

The difference of the median scores among the 3 groups were statistically significant in all aspects. In pairwise comparison, group III, whose participants had never used the EDG after the primary research, rated 
Table 3 Results of Multiple Logistic Regression of Never Use EDG Device

\begin{tabular}{|c|c|c|c|c|}
\hline & $\mathbf{b}^{\#}$ & $\begin{array}{l}\text { Adjusted } \\
\text { OR }\end{array}$ & $95 \% \mathrm{Cl}$ & p-value \\
\hline $\begin{array}{l}\text { Supine position } \\
\text { when instilling drop }\end{array}$ & 3.55 & 34.87 & $4.97,244.4 I$ & $<0.001$ \\
\hline $\begin{array}{l}\text { No. of medications } \\
>1 \text { eye drop use }\end{array}$ & 1.66 & 5.28 & $1.02,27.40$ & 0.048 \\
\hline $\begin{array}{l}\text { Visual Field MD } \\
\text { score: } \leq-15\end{array}$ & 0.55 & 1.74 & $0.35,8.60$ & 0.498 \\
\hline
\end{tabular}

Note: $b^{\#}=$ Regression coefficient.

significantly lower scores in almost all aspects compared to the two other groups, except for the opinion toward reduction of eye drop waste (Table 4). The rating scores for reduction of eye drop waste were significantly different between group I and group III $(p=0.017)$, but not significantly different between groups II and III $(p=0.11)$.

At the end of the interview, we also asked about the limitations of the EDG. The results are shown in Table 5. The major disadvantage of this device was complexity and time consuming $(49.1 \%)$, followed by cleaning inconvenience $(38.6 \%)$, improper fit of bottles into the EDG (31.6\%), and aiming difficulties (31.6\%).

\section{Discussion}

Non-compliance including improper administration of medications is the major factor responsible for glaucoma treatment failure. Gupta reported that nearly $90 \%$ of the
A

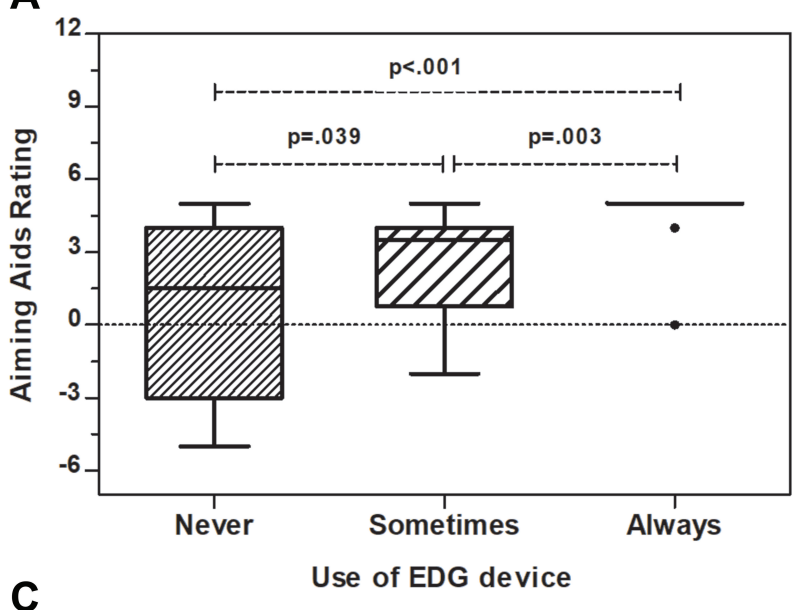

C

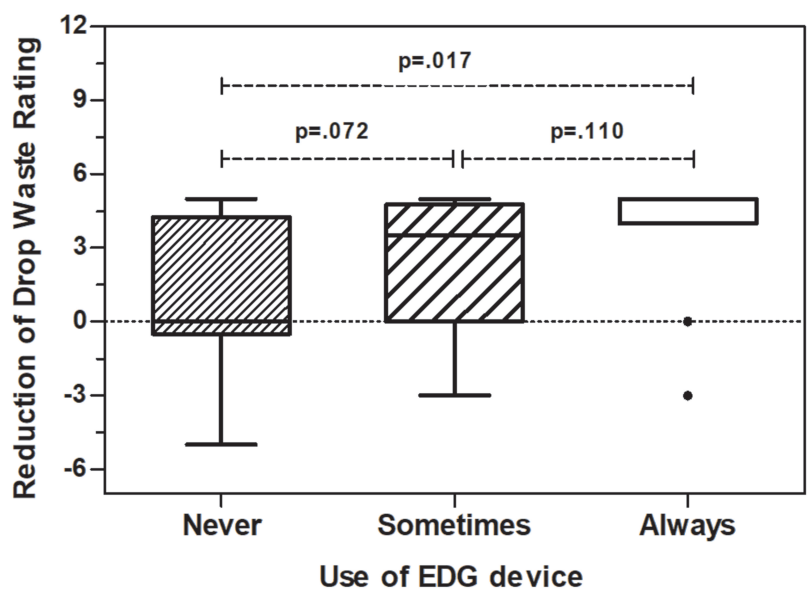

B
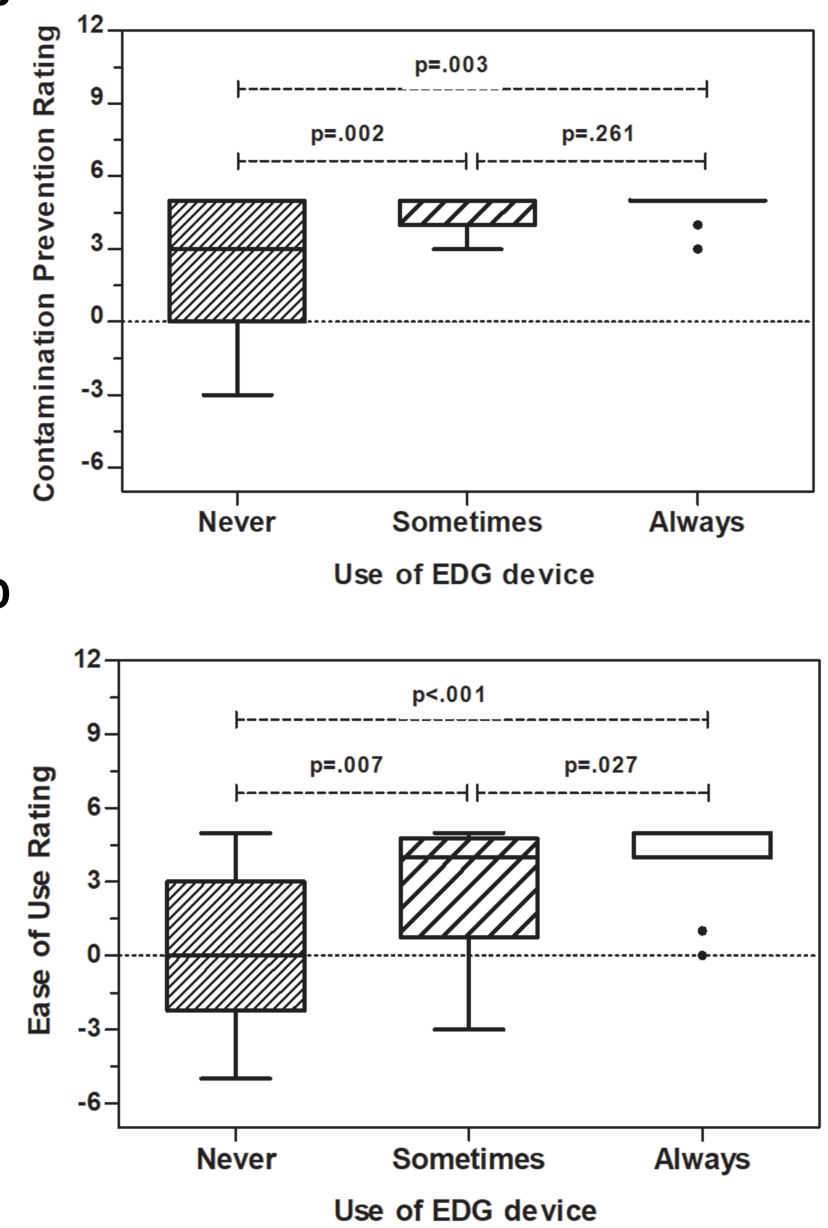

Figure 2 Rating scores of patients' opinion toward the EDG device. Rating scores toward; Aiming Aids (A), Contamination Prevention (B), Reduction of Drop Waste (C), and Ease of Use (D). 
Table 4 Comparison Between Groups for Scores of Opinions Toward EDG Device

\begin{tabular}{|c|c|c|c|c|c|c|c|}
\hline \multirow[t]{2}{*}{ Aspect } & \multicolumn{3}{|c|}{ Median Scores (Range) } & \multirow{2}{*}{$\begin{array}{l}\text { Kruskal-Wallis } \\
\text { Test (p) }\end{array}$} & \multicolumn{3}{|c|}{ Mann-Whitney U-Test (p) } \\
\hline & Gr. I & Gr. II & Gr. III & & $\begin{array}{l}\text { Gr. I vs } \\
\text { Gr. II }\end{array}$ & $\begin{array}{l}\text { Gr. I vs } \\
\text { Gr.III }\end{array}$ & $\begin{array}{l}\text { Gr. II vs } \\
\text { Gr.III }\end{array}$ \\
\hline Aiming aids & $5(0$ to 5$)$ & $3.5(-2$ to 5$)$ & $1.5(-5$ to 5$)$ & $<0.001$ & 0.003 & $<0.001$ & 0.039 \\
\hline Ease of use & $5(0$ to 5$)$ & $4(-3$ to 5$)$ & $0(-5$ to 5$)$ & $<0.001$ & 0.027 & $<0.001$ & 0.007 \\
\hline Contamination prevention & 5 (3 to 5$)$ & 5 (3 to 5$)$ & $3(-3$ to 5$)$ & $<0.001$ & 0.261 & 0.003 & 0.002 \\
\hline Reduction of drop waste & $5(-3$ to 5$)$ & $3.5(-3$ to 5$)$ & $0(-5$ to 5$)$ & 0.023 & 0.072 & 0.017 & 0.110 \\
\hline
\end{tabular}

Table 5 Limitations of EDG Device

\begin{tabular}{|l|l|}
\hline Limitations & N (\%) \\
\hline Complex and time consuming & $28(49.1)$ \\
Preparing and cleaning inconvenience & $22(38.6)$ \\
Improper fitting of medication bottles and device & $18(31.6)$ \\
Aiming difficulties with the device & $12(21.1)$ \\
Contamination potentials & $5(8.8)$ \\
Too much head tilt required & $4(7.0)$ \\
Unsuitable size of the device & $4(7.0)$ \\
Eye drop waste & $4(7.0)$ \\
Misaligned device with orbital rim & $2(3.5)$ \\
\hline
\end{tabular}

patients who administrated the topical glaucoma medications themselves were unable to instill eye drops correctly. $31 \%$ of patients had eye drops falling on eyelid or cheek and $75 \%$ had touched the tip of the bottle to globe or periocular tissue. ${ }^{13}$ These misdirected eye drops become wasted and lead to the prescription of additional medications for targeted intraocular pressure achievement which unnecessarily added the treatment cost. Moreover, the misdirected drops could result in local side effects, such as periocular hyperpigmentation from prostaglandins.

To solve the problems, many devices have been used and reported to improve the success rate of administering the first drop and decreasing contamination with eye lids. ${ }^{14-16}$ The desirable eye drop aids should be easy to use, reusable, fitted for most eyedrop bottles, and not expensive. ${ }^{11}$ From the primary study, the Thai EDG was able to prevent contamination and decrease the average number of eye drops used until successfully instilled into the eye. However, it failed to increase the success rate of administering the first drop and was not fitted to most of the eyedrop bottles. This could discourage glaucoma patients from using the device. We aimed to investigate which patients would like to continue using the EDG regularly and the factors associated with maintaining the EDG use.
The results of this study showed that almost half of the participants had never used the EDG device to aid eye drop instillation at home. The success they achieved with either technique is not associated with their choices of how to self-administer eye drops. Only $19.3 \%$ of the patients continued using the EDG regularly, while most of them (45.6\%) had never used the device after finishing the primary study. This result was similar to a previous study. Salyani reported that $74 \%$ of patients preferred to administer their eye drops without guide and $71 \%$ did not wish to continue using the guide after they received the device with instructions for a 1 week period. ${ }^{17}$

Salyani's study demonstrated the negative correlation between the number of doses per day and the ease of administering drops with the guide, as well as the negative correlation between the duration of self-administration and the wish to continue using the guide. Similarly, our study found that participants who controlled glaucoma with 2 or more medications were less likely to use the device. The process of eye drop administration with the EDG was found to be almost twice as long compared to the Traditional technique in a primary study. ${ }^{12}$ The greater number of eye drops being used, the longer it will take each administration time. Also handling eye drop bottles together with the EDG is not effortless if they are not fitted. If some or none of the medications are fitted with the device a more complicated administration process would be expected. However, this factor is not found to be independently associated with the participants' preference in multivariate analysis.

We also examined the correlation between the position when self-administering eye drops and the frequency of EDG use. From the primary study, all patients had practiced the EDG use in a supine position, however, the results in our study showed that the patients who instilled eye drops in a supine position used EDG the least compared with a sitting or standing position. This could be explained by the fact that the lying down position is the 
easiest way to perform self-instillation. It does not require head tilt and the patients already feel comfortable with their routine Traditional technique. Though tilting their head back enough to apply the device seems to be problematic to some participants, those who administer eye drops in sitting or standing positions are more likely to use it. Another explanation could be, since rinsing is recommended after each use, the device is usually stored near the cleaning area. Participants who administer eye drops in supine position might find it troublesome to pick up the device once they are already in bed and ready to administer medications.

Vision and visual field function did not affect the frequency of EDG use as there was no correlation between BCVA, MD and the frequency of EDG use. In general, the patients with impaired vision could have more difficulty in performing self-instillation and may have found that the EDG is more useful. On the contrary, Ritch's study showed that the patients with decreased visual acuity had to use proprioception instead of vision to allow them to take their eye drops precisely. ${ }^{18}$ With the EDG, their proprioceptive sensation could be disturbed.

The most obvious limitation in this research was that of a small sample size. We included only the subjects from the primary research about the efficacy of the EDG because they received the standardized training on how to self-instill eye drops both by Traditional technique and with the EDG. Although almost all of the subjects agreed to participate in this study, the number of subjects might not be enough to find the statistical difference between groups. EDG cannot be fitted with most of the eyedrop bottles. Although this did not affect the frequency of EDG use, it could affect the overall preference of the device. The other limitation was that we assessed the patients' opinions by the telephone questionnaire. Despite its advantage in assessing the illiterate patients, it may not reflect the true opinions since the patients could not feel as comfortable as when taking a paper questionnaire. Moreover, the patients' long-term compliance with EDG was not investigated in this study.

\section{Conclusion}

Despite the intention to improve glaucoma patients' compliance with their medications by using the EDG, only particular groups of patients preferred to use it. According to our study, the patients who had one medication and administrated their eye drops in a standing or sitting position tended to use the EDG more frequently and they should be the target group for EDG prescription. Although the regular EDG users were proved to have positive opinions on the guide further study on their longterm adherence with the EDG is required.

\section{Ethics Statement}

The study was approved by the Siriraj Institutional Review Board, Faculty of Medicine Siriraj Hospital, Mahidol University, Bangkok, Thailand [Si 122/2013]. The study complied with the principles of the Declaration of Helsinki and the International Conference on Harmonization in Good Clinical Practice (ICH-GCP).

\section{Acknowledgments}

We are grateful to Assistant Professor Dr. Chulaluk Komoltri from the Office for Research and Development, Faculty of Medicine Siriraj Hospital, Mahidol University, for her assistance in the statistical analysis.

\section{Funding}

No funding was received for this research.

\section{Disclosure}

The authors report no conflicts of interest in this work.

\section{References}

1. Collaborative Normal-Tension Glaucoma Study Group. The effectiveness of intraocular pressure reduction in the treatment of normal-tension glaucoma. Am J Ophthalmol. 1998;126(4):498-505. doi:10.1016/S0002-9394(98)00272-4

2. The AGIS Investigators. The Advanced Glaucoma Intervention Study (AGIS):7. The relationship between control of intraocular pressure and visual field deterioration. Am J Ophthalmol. 2000;130(4):429-440. doi:10.1016/S0002-9394(00)00538-9

3. Mills RP, Janz NK, Wren PA, et al. Correlation of visual field with quality of life measures at diagnosis in the Collaborative Initial Glaucoma Treatment Study (CIGTS). J Glaucoma. 2001;10 (3):192-198. doi:10.1097/00061198-200106000-00008

4. Kass MA, Heuer DK, Higginbotham EJ, et al. The Ocular Hypertension Treatment Study: a randomized trial determines that topical ocular hypotensive medication delays or prevents the onset of primary open angle glaucoma. Arch Ophthalmol. 2002;120 (6):701-713. doi:10.1001/archopht.120.6.701

5. Heijl A, Leske MC, Bengtsson B, et al. Early Manifest Glaucoma Trial Group: reduction of intraocular pressure and glaucoma progression: results from the early manifest glaucoma trial. Arch Ophthalmol. 2002;120(10):1268-1279. doi:10.1001/archopht.120.10.1268

6. Okeke CO, Quigley HA, Jampel HD, et al. Adherence with topical glaucoma medication monitored electronically the Travatan Dosing Aid study. Ophthalmology. 2009;116(2):191-199. doi:10.1016/j. ophtha.2008.09.004

7. Friedman DS, Quigley HA, Gelb L, et al. Using pharmacy claims data to study adherence to glaucoma medications: methodology and findings of the Glaucoma Adherence and Persistency Study (GAPS). Invest Ophthalmol Vis Sci. 2007;48(11):5052-5057. doi:10.1167/ iovs.07-0290 
8. Nordstrom BL, Friedman DS, Mozaffari E, et al. Persistence and adherence with topical glaucoma therapy. Am J Ophthalmol. 2005;140(4):598-606. doi:10.1016/j.ajo.2005.04.051

9. Nelson JD. Corneal abrasion resulting from a unit dose artificial tear dispenser. Am J Ophthalmol. 1987;103(3I):333-334.

10. Kholdebarin R, Campbell RJ, Jin Y-P, et al. Multicenter study of compliance and drop administration in glaucoma. Can J Ophthalmol. 2008;43(4):454-461. doi:10.3129/i08-076

11. Davies I, Williams AM, Muir KW. Aids for eye drop administration. Surv Ophthalmol. 2017;62(3):332-345. doi:10.1016/j.survophthal.20 16.12.009

12. Sakiyalak D, Maneephagaphun K, Metheetrairat A, et al. The effect of the Thai "Eye Drop Guide" on success rate of eye drop selfinstillation by glaucoma patients. Asian Biomed. 2014;8(2):22 1-227. doi:10.5372/1905-7415.0802.282

13. Gupta R, Patil B, Shah BM, et al. Evaluating eye drop instillation technique in glaucoma patients. J Glaucoma. 2012;21(3):189-192. doi:10.1097/IJG.0b013e31820bd2e1
14. Winfield AJ, Jessiman D, Williams A, et al. A study of the causes of non-compliance by patients prescribed eyedrops. $\mathrm{Br} J$ Opthalmol. 1990;74(8):477-480. doi:10.1136/bjo.74.8.477

15. Strungaru MH, Peck J, Compeau EC, Trope GE, Buys YM. Mirrorhat device as a drop delivery aid: a pilot study. Can J Ophthalmol. 2014;49(4):333-338. doi:10.1016/j.jcjo.2014.04.012

16. Davies IJ, Brown NH, Wen JC, et al. An upright eyedrop bottle: accuracy, usage of excess drops, and contamination compared to a conventional bottle. Clin Ophthalmol. 2016;10:1411-1417. doi:10.2147/OPTH.S104751

17. Salyani A, Birt C. Evaluation of an eye drop guide to aid self-administration by patients experienced with topical use of glaucoma medication. Can J Ophthalmol. 2005;40(2):170-174. doi:10.10 16/S0008-4182(05)80028-6

18. Ritch R, Jamal KN, Gürses-Özden R, et al. An improved technique of eye drop self-administration for patients with limited vision. $A m$ $J$ Ophthalmol. 2003;135(4):530-533. doi:10.1016/S0002-9394(02) 02017-2
Clinical Ophthalmology

\section{Publish your work in this journal}

Clinical Ophthalmology is an international, peer-reviewed journal covering all subspecialties within ophthalmology. Key topics include: Optometry; Visual science; Pharmacology and drug therapy in eye diseases; Basic Sciences; Primary and Secondary eye care; Patient Safety and Quality of Care Improvements. This journal is indexed on PubMed

\section{Dovepress}

Central and CAS, and is the official journal of The Society of Clinical Ophthalmology (SCO). The manuscript management system is completely online and includes a very quick and fair peer-review system, which is all easy to use. Visit http://www.dovepress.com/ testimonials.php to read real quotes from published authors. 